\title{
NGHIÊN CỨU MộT Số ĐĂC ĐIỂM LÂM SÀNG ĐộNG KINH TẠI TİNH AN GIANG
}

\begin{abstract}
TÓM TẮT.
Đắt vấn đề: Đặc điểm lâm sàng động kinh giúp chúng ta phân loại cợn động kinh và từ đó có phương pháp điều trị phù hợp. Đối tượng và phương pháp nghiên cứu: Nghiên cứu cắt ngang mô tả trên 864 bệnh nhân động kinh, thời gian nghiên cứu từ tháng 01 năm 2020 đến tháng 12 năm 2020. Kết quả nghiên cứu: Trong số 864 bệnh nhân động kinh được chọn vào mẫu nghiên cứu, kết quả cơn động kinh toàn thể chiếm $68,2 \%$, cơn động kinh cục bộ chiếm 27,4\%, cơn động kinh không phân loại chiếm $4,4 \%$. Giới nam chiếm $63,2 \%$ nhiều hơn nữ, trình độ học vấn cấp một chiếm 42,5\%, nguyên nhân động kinh do u não chiếm 2,3\%, chấn thương sọ não chiếm $8,9 \%$, đột quị não chiếm $21,3 \%$. Kết luận: Loại cơn đô̂ng kinh toàn thể chiếm chú yếu, giới nam nhiều hơn nữ, đa số động kinh chưa tìm được nguyên nhân.
\end{abstract}

\section{SUMMARY}

\section{STUDY SOME EPILEPSY CHARACTERISTICS} IN AN GIANG PROVINCE

Background: Epilepsy characteristics help us to classify seizures and to provide appropriate treatment. Patients and methods: Cross-sectional study design including 864 persons who admitted to An giang hospital from February $1^{\text {st }} 2020$ to August 31 th 2020. Results: Among 864 epilepsy patients selected into the study sample, the results of generalized seizures accounted for $68,2 \%$, partial seizures accounted for $27,4 \%$, and unclassified seizures accounted for $4,4 \%$. Males accounted for $63,19 \%$ more than females, primary education level accounted for $42,5 \%$, epilepsy caused by brain tumors accounted for $2,3 \%$, traumatic brain injury accounted for $8,9 \%$, stroke accounted for $21,3 \%$. Conclusion: Generalized epilepsy predominates, males are more than females, most seizures have no known cause.

\section{I. ĐĂT VẤN ĐỀ}

Động kinh là một trong những rối loạn thần kinh mãn tính và phổ biến nhất có thể ảnh hưởng đến từng cá nhân ở mọi lứa tuổi. Đã có khoảng 50 triệu người mắc bệnh động kinh trên toàn thế giới vào năm 2016. Gánh nặng bênh tật toàn cầu năm 2010 của WHO nghiên cứu xểp hạng động kinh là rối loạn thần kinh nặng thứ hai về khuyết tật. Động kinh có thể ảnh hưởng

\footnotetext{
${ }^{1}$ Bệnh viện Đa khoa Trung tâm An Giang ${ }^{2}$ Oai hoc Y Dước Thành phố Hồ Chí Minh. Chịu trách nhiệm chính: Mai Nhật Quang Email: bsquangag@gmail.com

Ngày nhận bài: 13.9.2021

Ngày phản biên khoa hoc: 2.11.2021

Ngày duyệt bài: 15.11.2021
}

Mai Nhật Quang1, Lê Văn Tuấn²

xấu đến chất lượng cuộc sống của mỗi cá nhân vì sự hiện diện của chấn thương thể chất liên quan đến động kinh, không có khả năng làm việc hoặc đi học, tác dụng phụ của điêu trị thuốc, các bệnh đi kèm, tình trạng suy nhược tâm lý xã hội, phát triển thành cơn động kinh kháng thuốc và tử vong sớm[6, 7].

Chi phí kinh tế hàng năm của bệnh động kinh được ước tính là khoảng 12,5 tỷ đô la, trong đó 1,7 tỷ đô la (14\%) là chi phí y tế trực tiếp và 10,8 tỷ đô la (86\%) liên quan đến mất việc làm và khả năng kiếm tiền. Khoảng $25 \%$ những người bị động kinh thất nghiệp vì tình trạng bệnh của họ. Gánh nặng to lớn của động kinh đối với xã hội về cơ bản có liên quan đến sự hiểu biết hạn chế của chúng ta về các quá trình sinh học cở bản của cơn động kinh và sự hình thành động kinh, mặc dù chúng ta đã có nhiêu nghiên cứu sử dụng các phương pháp tiếp cận với bệnh động kinh[7].

Các nghiên cứu về đặc điểm động kinh sẽ cung cấp các dữ liệu làm phong phú thêm hiểu biết của chúng ta về bản chất của động kinh, làm cơ sở cho việc hoạch định kế hoạch chăm sóc sức khỏe cho các bệnh nhân động kinh và dự phòng các yếu tố nguy cơ làm giảm tỷ lệ mắc động kinh. Chúng tôi tiến hành nghiên cứu đề tài: "Nghiên cứu một số đặc điểm động kinh tại tỉnh An Giang" với mục tiêu:

1. Đặc điềm dân số học động kinh tại tỉnh An Giang.

2. Phân loại cơn động kinh theo bảng phân loại động kinh năm 2017.

Chúng tôi hi vọng kết quả nghiên cứu sẽ góp phần phong phú hơn về dữ liệu động kinh tại khu vực đồng bằng sông Cửu Long cũng như của cả nước.

\section{II. ĐỐI TƯỢNG VÀ PHƯƠNG PHÁP NGHIÊN CỨU}

Đối tượng nghiên cứu: Các bệnh nhân động kinh từ cộng đồng dân cư 160.2336 người của dân số nghiên cứu gồm 24 xã phường trên địa bàn tỉnh An Giang.

Tiêu chuẩn chon bênh: Bênh nhân được chẩn đoán động kinh theo tiêu chuẩn liên đoàn động kinh quốc tế, khi có ít nhất hai cơn động kinh không có yếu tố kích gợi xảy ra cách nhau $>24$ giờ.

Tiêuu chuẩn loại trừ: Các trường hợp co giật cấp không phải động kinh như hạ natri máu, 
tăng đường huyết, hạ đường huyết.

Phương pháp nghiên cứu

Thiết kế nghiên: Nghiên cứu cắt ngang mô tả tiến cứu.

Thời gian nghiên cứu: Thời gian nghiên cứu từ tháng 01 năm 2020 đến 31 tháng 12 năm 2020.

Địa điểm nghiên cứu: Cộng đồng dân cư tỉnh An Giang.

Cỡ mẫu nghiên cứu: được tính theo công thức

$$
N=\frac{Z_{(1-\infty / 2)}^{2} X P(1-P)}{d^{2}}
$$

Trong đó: $\mathrm{N}$ : Số mẫu cần nghiên cứu; $\mathrm{Z}^{2}{ }_{(1-a / 2)}$ $=1,96$ với khoảng tin câyy $95 \%$; $\varepsilon$ : sai số tương đối 0,$1 ; d^{2}=(\varepsilon \times P)^{2}=(0,1 \times 0,005)^{2}$.

$$
\mathrm{N}=\frac{1,96^{2} X 0,005(1-0,05)}{\left(0,1 X_{0,005}\right)^{2}}=76.448
$$

Do chọn mẫu theo kỹ thuật chọn mẫu cụm nên cỡ mẫu cần phải chọn bằng cỡ mẫu tính được nhân 2 lần, do đó cở mẫu cần nghiên cứu là 152.896 người.

Phương pháp phân tích và xử lý số liệu: Số liệu được xử lý trên phần mềm SPSS 22.

\section{KẾT QUẢ NGHIÊN CỨU}

Trong thời gian nghiên cứu từ tháng 01 năm 2020 đến 31 tháng 12 năm 2020, chúng tôi tiến hành sàng lọc 160.236 hộ gia đình trong dân số nghiên cứu, chúng tôi chọn được 864 bệnh nhân thỏa điều kiện vào mẫu nghiên cứu.

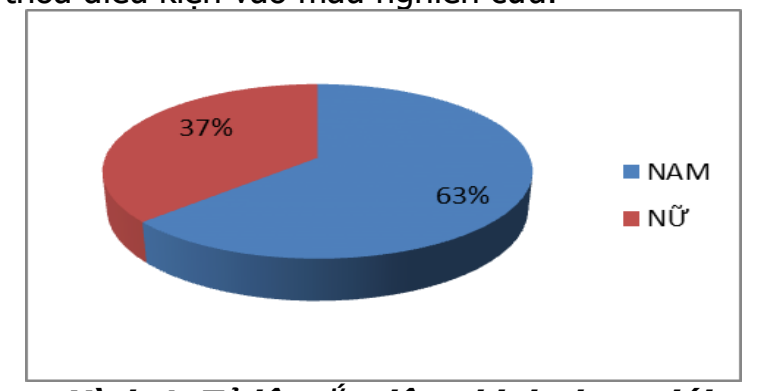

Hình 1. Tỷ lệ mắc động kinh theo giới

Nhận xét: Trong nghiên cứu số bệnh nhân động kinh nam (546/864) chiếm $63 \%$, số bệnh nhân động kinh nữ (318/864) chiếm 37\%.

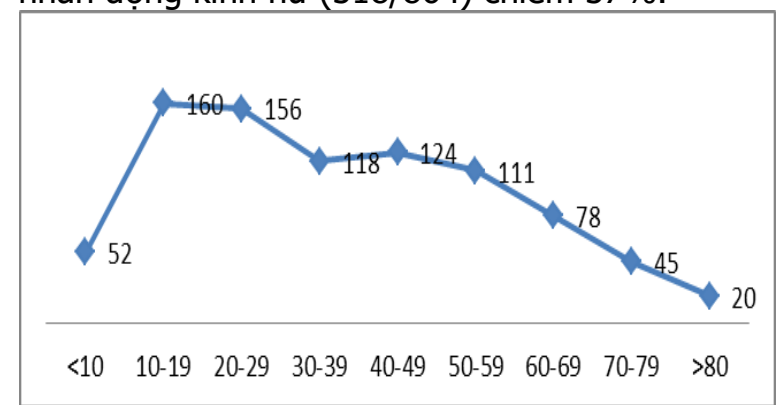

Hình 2. Nhóm tuổi mắc động kinh
Nhận xét: Nhóm tuổi 10-19 mắc động kinh nhiều nhất, sau đó tỷ lệ mắc động kinh giảm dần theo thời gian, nhóm tuổi có tỷ lệ mắc ít nhất là trên 80 tuổi.

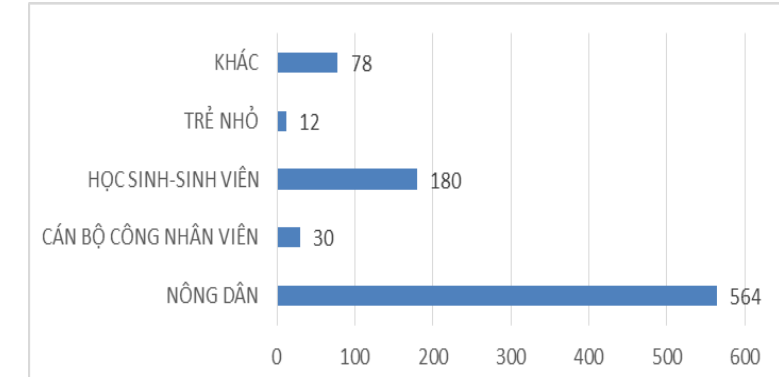

Hình 3. Tý lệ mắc động kinh theo nghề nghiệp

Nhận xét: Trong nghiên cứu nhóm mắc bệnh có nghề nghiệp nông dân chiếm đa số $464 / 864$, tiếp theo là học sinh-sinh viên có 180/864, cán bộ công nhân viên 30/864.

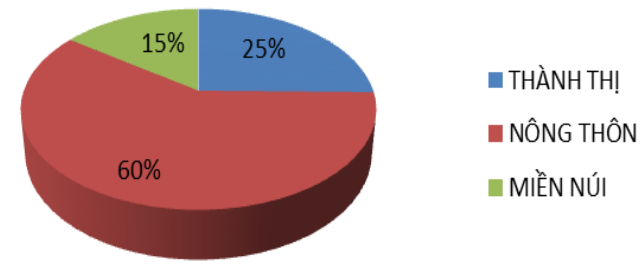

\section{Hinh 4. Tỷ lệ mắc động kinh theo khu vực cư trú}

Nhận xét: Tỷ lệ mắc động kinh nhiêu ở khu vực nông thôn $60 \%$, sau đó là khu vực thành thị và cuối cùng là khu vực miền núi.

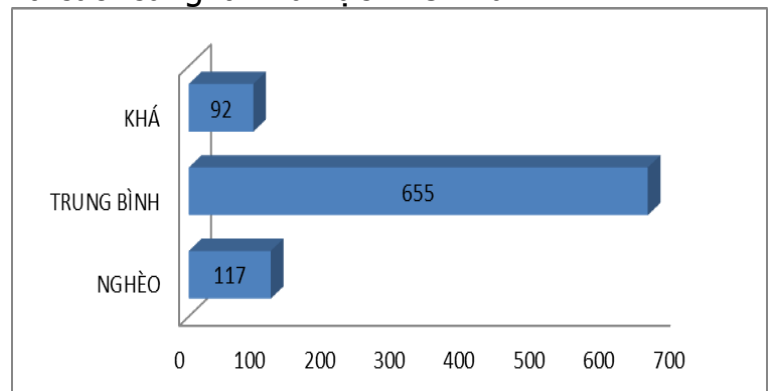

Hình 5. Tình trạng kinh kế ở bệnh nhân mắc động kinh

Nhận xét: Trong số các gia đình bênh nhân động kinh có thu nhận trung bình chiểm đa số 655/864.

Bảng 1. Thời gian mang bênh động kinh

\begin{tabular}{|c|c|c|}
\hline $\begin{array}{c}\text { Thời gian mang } \\
\text { beênh }\end{array}$ & $\begin{array}{c}\text { Số beênh } \\
\text { nhần }\end{array}$ & Tỷ lệ \\
\hline Dưới 1 năm & 173 & $20 \%$ \\
\hline $1-5$ năm & 349 & $40,4 \%$ \\
\hline $6-10$ năm & 260 & $30,1 \%$ \\
\hline \multicolumn{2}{|l}{} \\
\hline
\end{tabular}




\begin{tabular}{|c|c|c|}
\hline Trên 10 năm & 82 & $9,5 \%$ \\
\hline Tống & $\mathbf{8 6 4}$ & $\mathbf{1 0 0 \%}$ \\
\hline
\end{tabular}

Nhân xét: Thời gian mang bệnh động kinh từ 1 đến 5 năm chiếm đa số $40,4 \%$, thời gian mang bệnh từ 6-10 năm chiếm $30,1 \%$.

\begin{tabular}{|c|c|c|c|c|}
\hline \multirow{2}{*}{$\begin{array}{l}\text { Loại cơn động } \\
\text { kinh }\end{array}$} & \multicolumn{3}{|c|}{ Hình ảnh sóng trên điện não đồ } & \multirow{2}{*}{ Tổng n(\%) } \\
\hline & Điến hình n(\%) & Không điến hình n(\%) & Bình thường n(\%) & \\
\hline Toàn thế & $156(72,9)$ & $205(62,3)$ & $223(71,9)$ & $584(68,5)$ \\
\hline Cuc bô & $49(22,9)$ & $109(33,1)$ & $73(23,5)$ & $231(27,1)$ \\
\hline Không phân loại & $9(4,2)$ & $15(4,6)$ & $14(4,5)$ & $38(4,5)$ \\
\hline Tống & 214 & 329 & 310 & 853 \\
\hline
\end{tabular}

Nhận xét: Trong nghiên cứu sóng điện não điến hình chiếm $214 / 853(25,1 \%)$, sóng điện não không điển hình chiếm 329/853 (35,6\%), sóng điện não bình thường chiếm 310/853 (39,3\%).

Bảng 3. Tỷ lệ hiện mắc động kinh liên quan trinh độ học vấn

\begin{tabular}{|c|c|c|c|}
\hline Trình độ hộc vấn & Số trường hợp động kinh & Tỳ lệ \%o & Khoảng tin cậy 95\% \\
\hline Mù chứ & 160 & $18,5 \%$ & $16 \%-21,4 \%$ \\
\hline Cấp 1 & 367 & $42,5 \%$ & $39,1 \%-45,7 \%$ \\
\hline Cấp 2 & 211 & $24,4 \%$ & $21,4-27,3 \%$ \\
\hline Cấp 3 & 88 & $10,2 \%$ & $8,2 \%-12,3 \%$ \\
\hline Cao đăng - Đại học & 38 & $4,4 \%$ & $3,1-5,9 \%$ \\
\hline
\end{tabular}

Nhân xét: Các bểnh nhân đônng kinh có trình độ học vấn cấp 1 là cao nhất chiếm $42,5 \%$, trình độ học vấn cấp 2 chiếm $24,4 \%$, trình độ cấp 3 chiếm 10,2\%, trình độ cao đẳng đại học chiếm 4,4\%.

Bảng 4. Phân loại cớn động kinh theo giới tính

\begin{tabular}{|c|c|c|c|}
\hline Loại cơn động kinh & Tống N(\%; CI 95\%) & Nam N(\%; CI 95\%) & Nữ N(\%; CI 95\%) \\
\hline Toàn thể & $589(68,2 \% ; 64,9-71,2)$ & $374(68,5 \% ; 64,3-72,4)$ & $215(67,6 \% ; 62,3-72,8)$ \\
\hline Cục bộ & $237(27,4 ; 14,4 \%-30,7)$ & $145(26,6 \% ; 22,8-30,3)$ & $92(28,9 \% ; 24-33,7 \%)$ \\
\hline Không phân loại & $38(4,4 \% ; 3-5,8)$ & $27(4,9 \% ; 3,3-6,8)$ & $11(3,5 \% ; 1,5-5,6)$ \\
\hline
\end{tabular}

Nhận xét: Trong nghiên cứu loại cơn động kinh toàn thế là chủ yếu chiếm $(68,2 \%)$, sau đó là loại cơn động kinh cục bộ chiếm 27,4\% và động kinh không phân loại chiếm 4,4\%.

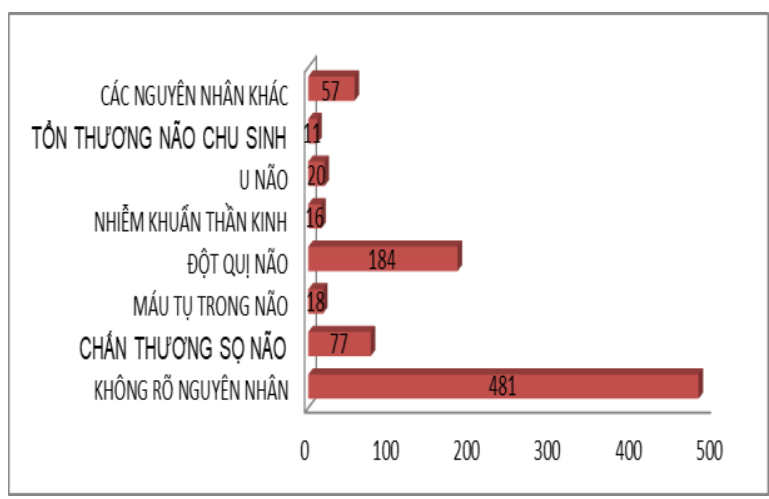

Hình 6. Nguyên nhân gây động kinh

Nhận xét: Trong các nguyên nhân động kinh khảo sát được, đột quị não có 184/864 trường hợp, u não có 20/864 trường hợp, chấn thương sọ não có 77/864 trường hợp.

\section{BÀN LUÂिN}

Tuổi: Trong nghiên cứu của chúng tôi, tuổi trung bình của các bệnh nhân động kinh là $37,03 \pm 20,22$ tuổi, trường hợp tuổi cao nhất là 90 tuổi (có một bệnh nhân) là tuổi thấp nhất 01 tuổi (có một bệnh nhân). Khi xem xét theo nhóm tuổi, nhóm tuổi dưới 40 có tỷ lệ bệnh nhân mắc nhiều hơn so với nhóm tuổi trển 40 . Nhóm tuổi có tỷ lệ mắc cao nhất là nhóm tuổi từ 10-19 tuổi (hình 2). Nghiên cứu của tác giả Nguyễn Anh Tuấn cho thấy nhóm tuổi 35-44 chiếm tỷ lệ cao nhất 25,5\%[5].

Giới: Tỷ lệ mắc động kinh ở giới nam nhiều hơn giới nữ ở mọi lứa tuổi và ở tất cả các loại động kinh, điều này có lẽ là do nam giới dễ bị các yếu tố nguy cơ động kinh so với giới nữ như chấn thương đầu do di chuyển nhiều trên đường dễ bị tai nạn giao thông, làm các công việc nặng nhọc dễ bị tai nạn sinh hoạt cũng như tai nạn lao động. Kết quả nghiên cứu của chúng tôi cũng tương tự như nghiên cứu của tác giả Nguyễn Anh Tuấn Và Nguyễn Văn Hướng[ 3,5$]$.

Cư trú: Nghiên cứu của chúng tôi cho thấy tỷ lệ mắc động kinh ở thành thị thấp hơn so với nông thôn và miền núi. Điều này có thể lý giải vì khu vực thành thị có điều kiện kinh tế, văn hóa, y tế, dân trí và mức sống cao hơn so với khu vực nông thôn và miền núi do vậy người dân được chăm sóc y tế tốt hơn, giáo dục tốt hơn, dân trí cao hơn nên tỷ lệ mắc động kinh thấp hớn so với các ku vực khác. Khu vực nông thôn và miên núi do kinh tế khó khăn, dân trí chưa cao, trang thiết bị $y$ tế nghèo nàn, điêu kiện vệ sinh còn kém làm tăng nguy cơ các bệnh viêm não, viêm màng 
não, nhiễm ký sinh trùng,... việc quan tâm chăm sóc sức khỏe ban đầu chưa tốt, khi mắc bệnh còn điêu trị theo dân gian và không tuân thủ điều trị làm cho tỷ lê mắc động kinh cao hơn so với các khu vực khác.

Trình độ học vấn: Trong nghiên cứu của chúng tôi, tỷ lệ mắc động kinh ở nhóm bệnh nhân có trình độ học vấn tiểu học chiếm cao nhất 367/864 (42,5\%), nhóm người có trình độ cấp hai chiếm 211/864 (24,4\%), nhóm người bệnh có trình độ cấp ba chiếm 88/864 (10,2\%), nhóm người có trình độ cao đẳng - đại học chiếm 38/864 (4,4\%), nhóm bệnh nhân mù chũ chiếm 160/864 (18,5\%). Nghiên cứu của tác giả Nguyễn Văn Hướng tại xã Phù Linh cho thấy nhóm người không biết chữ cao nhất chiếm $24 \%$, nhóm người có trình độ tiểu học chiếm $9,3 \%$, trình độ trung học cơ sở chiếm $4,8 \%$, trung học phổ thông trở lên chiếm 5,5\%[3].

Nhóm tuổi: Trong nghiên cứu của chúng tôi, tại cộng đồng dân cư tỉnh An Giang nhóm có thời gian mang bệnh động kinh từ 1 đến 5 năm chiếm tỷ lệ cao nhất 349/864 (40,4\%), thời gian mang bệnh động kinh dưới một năm chiếm 173/864 (20\%), thời gian mang bệnh động kinh từ 6 đến 10 năm chiếm 260/864 $(30,1 \%)$, thời gian mang bệnh trên 10 năm chiếm 82/864 $(9,5 \%)$. Thời gian mang bệnh từ 1 đến 5 năm cao có thể do người dân thiếu kiến thức về bệnh động kinh, cũng như mặt cảm về bệnh, đặc biệt ở vùng nông thôn và miền núi nhân dân còn tồn tại những quan niệm sai lầm về bệnh tật đặc biệt là bênh đông kinh làm cho người thân sợ hãi che che dấu. Khi bệnh nặng hoặc có nhiều cơn động kinh thì người thận mới đưa bệnh nhân đến cơ sở y tế. Ngoài ra, còn phụ thuộc vào trình độ và mạng lưới y tế cơ sở nới bệnh nhân sinh sống.

Loại động kinh: Kết quả nghiên cứu của chúng tôi cho thấy động kinh toàn thể chiếm 589/864 $(68,2 \%)$, động kinh cục bộ chiếm 237/864 $(27,4 \%)$, động kinh không phân loại chiếm $38 / 864(4,4 \%)$. Nghiên cứu của tác giả Nguyễn Thúy Hường tỷ lệ động kinh toàn thể chiếm $74,8 \%$, nghiên cứu của tác giả Cao Tiến Đức tỷ lệ động kinh toàn thể chiếm $60,8 \%$. Loại cơn động kinh toàn thể trong nghiên cứu của chúng tôi tương tự như nghiên cứu của tác giả Dương Huy Hoàng, động kinh toàn thể chiếm 69,4\%[2].

Nguyên nhân động kinh: Trong nghiên cứu của chúng tôi có $77 / 864$ trường hợp động kinh có tiên căn chấn thướng sọ não chiếm 8,9\%. Nghiên cứu của tác giả Dương Huy Hoàng nguyên nhân chấn thương sọ não chiếm 23,9\%, tác giả Nguyễn Thúy Hường động kinh do chấn thương sọ não chiếm $11,5 \%[1,2]$.

Trong nghiên cứu của chúng tôi u não có 20/864 trường hợp chiếm 2,3\%, nghiên cứu của tác giả Dương Huy Hoàng u não chiếm 4,1\%[1]. Nghiên cứu của tác giả Ngô Tất Thành u não là nguyên nhân chính gây động kinh ở người trên 60 tuổi tỷ lệ 3,2\%[4]. Điều khác biệt này là do các tác giả nghiên cứu động kinh trển người lớn và nghiên cứu trong bệnh viện. Các bệnh nhân mắc động kinh đều được chụp cắt lớp vi tính sọ não hoặc chụp cộng hưởng từ.

Điện não đồ: Trong nghiên cứu của chúng tôi cho thấy sóng điện não điển hình có $214 / 853$ chiếm $25,1 \%$, sóng điện não không điển hình có $329 / 853$ chiếm $(38,6 \%)$, sóng điện não đồ bình thường có $310 / 853$ chiếm $36,3 \%$. Nghiên cứu của tác giả Dương Huy Hoàng cho thây sóng kích phát điển hình chiếm 33,3\% trên bản ghi điện não, dạng điện não biến đổi không đặc hiệu chiếm $45 \%$, dạng điện não đồ trong giới hạn bình thường chiếm 21,7\%[1]. Khi nghiên cứu tại bệnh viện, các tác giả có điều kiện ghi điện não đồ trong cớn và ghi nhiều lần. Trái lại, nghiên cứu dịch tễ chủ yếu ghi điện não ngoài cơn, ghi ít lần hơn và nhiều bệnh nhẩn có cơn động kinh thưa.

Khi phân loại sóng điện não theo cơn động kinh, chúng tôi nhận thấy sóng điện não đồ điển hình có 156/214 chiếm 72,9\% trong động kinh toàn thể, có $49 / 214$ chiếm $22,9 \%$ trong động kinh cục bộ và $9 / 214$ chiếm $4,2 \%$ trong động kinh không phân loại. Sóng điện não đồ khổng điển hình trong động kinh toàn thể có 205/39 chiếm $62,3 \%$, có $109 / 329$ chiếm $33,1 \%$ trong động kinh cục bộ, có $15 / 329$ chiếm 4,6\% trong động kinh không phân loại. Nghiên cứu của tác giả Dương Huy Hoàng cho thấy điện não đồ kịch phát điển hình loại động kinh cục bộ chiếm 52\%, loại động kinh toàn thể chiếm $38,1 \%$, không phân loại chiếm 36,7\%[1]. Tác giả Phan Việt Nga khi nghiên cứu động kinh toàn thể ở trẻ em ghi nhận điện não đồ điển hình ở động kinh toàn thể chiếm $56,8 \%$, không điển hình chiếm $25,6 \%[2]$. Theo chúng tôi sự khác biệt này là do trong lựa chọn bệnh nhân và tỷ lệ giữa các cơn động kinh cũng góp phần tạo ra sự khác biệt kết quả về dạng sóng điện não điển hình của chúng tôi với kết quả của các nghiên cứu khác.

\section{KẾT LUÂ̂N}

Qua nghiên cứu 864 bệnh nhân động kinh tại An Giang chúng tôi nhận thấy: nhóm tuổi 10-19 mắc động kinh nhiều nhất, động kinh không rõ nguyên nhân chiếm đa số. Các nguyên nhân động kinh thường gặp nhất là đột quị não, chấn 
thương sọ não, u não. Loại cơn động kinh thường gặp là động kinh toàn thể.

\section{TÀI LIÊU THAM KHẢO}

1. Dướng Huy Hoà̀ng (2009). Nghiên cứu một số đặc điểm dịch tể, lâm sàng động kinh, tình hình quản lý bệnh nhân động kinh tại tỉnh Thái Bình. Luân án Tiến sĩ Y học năm 2009.

2. Nguyê̂n Thúy Hường (2001). Nghiên cứu một số đặc điểm dịch tế và tình hình điêu trị động kinh tại cộng đồng tỉnh Hà Tây, Luận án Tiến sĩ Y học, Học viện Quân y.

3. Nguyến Vắn Hướng (2003). Dịch tễ động kinh tại xã Phù Linh, huyện Sóc Sơn, Hà Nội, Luận văn
Bác sĩ, Đai hoc Y Hà Nôii.

4. Ngố Tất Thà̀nh (2005). Nghiên cứu một số đăc điểm lâm sàng và cân lâm sàng của đông kinh khởi phát ở bệnh nhân tuổi từ 45 trở lên, Luận văn thạc sỹ $Y$ hoc, Học viện Quân y.

5. Nguyê̂n Anh Tuấn. (2007) "Tỷ lệ động kinh ở huyên $\mathrm{Ba}$ Vì.

6. Beghi E, Giussani G, Sander J W (2015). The natural history and prognosis of epilepsy. Epileptic Disord, 17 (3), 243-53.

7. Mohammad Q D, Saha N C (2020). Prevalence of epilepsy in Bangladesh: Results from a national household survey". 5 (4), 526-536.

\section{MộT SỐ THUÂN LỢI, KHÓ KHĂN TRONG THU, CHI TÀI CHÍNH BÊ̂NH VIỆN ĐA KHOA TỈNH ĐẮK NÔNG GIAI ĐOẠN 2018- 2020}

\section{TÓM TẮT}

Mục tiêu: Nghiên cứu phân tích một số yếu tố thuận lợi, khó khăn trong thu, chi tài chính Bệnh viện đa khoa tỉnh Đắk Nông giai đoạn 2018- 2020. Phương pháp nghiên cứu: Thiết kế nghiên cứu định tính sử dụng kỹ thuật phỏng vấn sâu và thảo luận nhóm với đại diện ban giám đốc bệnh viện, lãnh đạo phòng/ban chức năng, cán bộ y tế tại Bệnh viện đả khoa tỉnh Đắk Nông. Kết quả và kết luận: Các yếu tố thuân lợi gồmquy đinh về tư chủ tài chính của bệnh viện; Hoàn thiện các quy định, quy chế chi tiêu tài chính của bệnh viện; Quản lý, lãnh đạo của bệnh viện; Ứng dụng công nghể thông tin. Các yếu tố khó khăn gồm cần đối các nguồn thu chi của bệnh viện; Thiếu các văn bản hướng dẫn chi tiết, đồng bộ liên quan đến tài chính bệnh viện; Nhân lực còn thiếu về cả số lượng và chất lượng; Xuất toán BHYT; Tác động của bênh dich COVID-19.

Tứ khóa: tài chính bệnh viện, thuận lợi, khó khăn, Bệnh viện đa khoa tỉnh Đắk Nông.

\section{SUMMARY \\ SOME FAVORABLE AND UNFAVORABLE \\ FACTORS IN FINANCIAL REVENUE AND EXPENDITURE AT DAK NONG PROVINCIAL GENERAL HOSPITAL, 2018 - 2020}

Objective: To study several favorable and unfavorable factors in financial revenue and expenditure of Dak Nong Provincial General Hospital in the period of 2018-2020. Research Methods: Design a qualitative study using in-depth interview techniques and focus group discussions with representatives of

${ }^{1}$ Trường Đại Học Y tế Công Cộng,

2Bênh viên đa khoa tỉnh Đắk Nông

Chịu trách nhiệm chính: Nguyễn Quỳnh Anh

Email: nqa@huph.edu.vn

Ngày nhận bài: 10.9.2021

Ngày phản biên khoa hoc: 29.10.2021

Ngày duyệt bài: 12.11.2021

\section{Nguyễn Quỳnh Anh"1, Trần Thanh Bình ${ }^{2}$}

the hospital's board of directors, leaders of functional departments/departments, medical staff at Dak Nong Provincial General Hospital. Results and conclusions: Favorable factors include regulations on financial autonomy of hospitals; Completing the hospital's financial spending regulations and regulations; Management and leadership of the hospital; Information technology applications. Unfavorable factors include balancing the hospital's revenues and expenditures; Lack of detailed and synchronous guiding documents related to hospital finance; Human resources are lacking in both quantity and quality; Export health insurance payment; Impact of the COVID-19 pandemic.

Keywords: hospital finance, favorable factors, unfavorable factors, Dak Nong Provincial General Hospital.

\section{I. ĐĂT VẤN ĐỀ̂}

Tài chính bệnh viện (TCBV) giữ vai trò vô cùng quan trọng đối với hoạt động của bệnh viện. Sau hớn 10 năm thực thi Nghị định 43/2006/NĐ-CP, hoạt động của các đơn vị sự nghiệp công lập trên thực tế đã phát sinh nhiêu vấn đề chưa phù hợp với tinh thân của Nghị định [1]. Nhằm hạn chế các bất cập của Nghị định 43/2006/NĐ-CP, Chính phủ đã ban hành Nghi định 16/2015/NĐ-CP để đáp ứng nhu câu đổi mới, phát triển hoạt động sự nghiệp [2]. Tiếp đó, Bộ Y tế bắt đầu thực hiện Chiến lược tài chính y tế giai đoạn 2016 - 2025, đưa ra một số giải pháp chung để hướng đến hệ thống y tế bền vững hơn [3]. Bệnh viện đa khoa tỉnh Đắk Nông là bệnh viện hạng II trực thuộc Sở Y tế tỉnh Đắk Nông. Trong những năm gân đây công tác khám chữa bệnh được duy trì thường xuyên, chất lượng điêu trị và phục vụ từng bước được cải thiện đáng kể, cơ bản đáp ứng nhu câu chăm sóc sức khỏe cho nhân dân trong tỉnh. Bệnh viện 